\title{
Introduction: the multiple facets of language studies
}

Rosane Silveira*

Universidade Federal de Santa Catarina

Florianópolis, SC, BR

Ilha do Desterro has been published since 1979, and issue 69.1 is a landmark in the sense that it inaugurates a new tradition for this journal: the publication of non-thematic issues dedicated to language studies. The current issue reflects the variety of research on language studies, with articles in the subfields of critical discourse analysis, cognition, teaching, learning, teacher education, and translation.

This issue is the first one prepared with the collaboration of a team of associate editors, namely, Mailce Borges Mota, the editor of thematic language issues; Magali Sperling Beck, the editor of non-thematic literature issues, and Rosane Silveira as the editor of non-thematic language issues. The participation of associate editors is intended to help Ilha do Desterro to offer a broader publishing scope by allowing both thematic and non-thematic issues for language and literature articles.

In nearly forty years of publication, Ilha do Desterro has compiled thematic issues related related to each of the subfields aforementioned. Some recent examples from the past five years are displayed below.
Table 1. Examples of thematic language issues of Ilha do Desterro

\begin{tabular}{ll}
\hline $\begin{array}{l}\text { Editors } \\
\text { Johnson \& Dellagnelo } \\
\text { (2015) }\end{array}$ & $\begin{array}{l}\text { Themes } \\
\text { L2/FL Teacher Educa- } \\
\text { tion: Bridging the com- } \\
\text { plexities of teaching and } \\
\text { the learning of teaching }\end{array}$ \\
$\begin{array}{l}\text { D'Ely \& Guará-Tavares } \\
\text { (2014) }\end{array}$ & $\begin{array}{l}\text { L2 Learning/teach- } \\
\text { ing and Technology: A } \\
\text { 'CALL' for a change? }\end{array}$ \\
Heberle \& Veloso (2013) & $\begin{array}{l}\text { Studies in Multimodality } \\
\text { Tomitch (2012) }\end{array}$ \\
$\begin{array}{l}\text { The Neuroscience of } \\
\text { Reading }\end{array}$ \\
Mota (2011) & $\begin{array}{l}\text { Recent Developments in } \\
\text { SLA }\end{array}$ \\
\hline
\end{tabular}

As Table 1 shows, teacher education was the central theme of the issue organized by Johnsons and Dellagnelo (2015), and this is the research topic of two articles included in the present collection. Language learning and technology is the focus of the issue organized by D'Ely and Guará-Tavares (2014), and the current Iha do Desterro also brings two articles that address this interface. Heberle and Veloso (2013) organized an issue on multimodality, a topic that is closely related to some of the discourse analysis articles published here. Tomitch (2012) compiled articles that investigated the

${ }^{*}$ Rosane Silveira is a faculty member of the Department of Foreign Language and Literature, and of the English Post-Graduation Program at the Federal University of Santa Catarina. She is a research fellow of the National Council for Scientific and Technological Development (CNPq). Her teaching and research interests involve the development and teaching of L2 speech. E-mail: rosanesilveira@hotmail.com. 
neurological aspects of reading, and a similar topic is examined by one article and the book review included here. Finally, Mota (2011) organized an issue on Second Language Acquisition research trends, and that Ilha do Desterro included papers on topics such as the role of working memory, aptitude, metalinguistic knowledge, and technology, for example. A number of the articles selected for the present issue address one or more of these variables too.

The advantage of having non-thematic issues is that from now on Ilha do Desterro will allow authors interested in other topics that haven't appeared in the most recent issues to have a publication venue for their papers. For example, translation studies, L2 phonetics and phonology, and critical discourse analysis are some of the topics that are expected to appear more frequently in this journal.

The current issue includes a collection of seventeen articles and one book review. As shown in Table 2, the contributors come from fourteen different Brazilian institutions and six international institutions, which shows the importance of Ilha do Desterro as a publication venue for authors investigating phenomena that is relevant for the fields of Applied Linguistics, Psycholinguistics, Pedagogy, Critical Discourse Analysis, and Translation.

Table 2. Affiliations of national and international collaborators

\section{Brazilian institutions}

Universidade de Santa Cruz do Sul

Universidade Federal de Viçosa

Universidade Federal de Sergipe

Universidade Federal de Santa Catarina

UNIRITTER

Universidade de Caxias do Sul

Universidade Federal do Ceará

Universidade Tecnológica Federal do Paraná

Universidade Federal do Paraná

Universidade Federal do Rio Grande do Sul

Universidade Federal de Minas Gerais

Universidade Federal de Campina Grande

Universidade Federal do Estado do Rio de Janeiro

Universidade do Estado da Bahia

Total: 14

\section{International institutions}

Middlebury College

Fordham University, New York

Iowa State University

Tambov State University

Tyumen State University

Université libre de Bruxelles

Total: 6

The articles are grouped according to the wmajor subfields they belong to, and are organized in the following order: cognition, teaching, learning, teacher education, critical discourse analysis, and translation. Information about each author and their e-mail (when authorized by the authors) are presented in the form of a footnote, right after the authors' names, on the first page of each article. In the following paragraphs, the reader will find a brief description of the topic addressed by each article.

The first five articles explore cognitive aspects of second or foreign language development. This section opens with an article from Souza, Soares-Silva, and Silva, who investigate language representation in bilingualism. More specifically, the authors pursue the question of whether knowledge of a second language (L2) syntax affects fist language (L1) metalinguistic awareness of constraints on a specific type of syntactic construction in Brazilian Portuguese. The study employed a psycholinguistic task that required [the] informants to focus on the form of L1 linguistic structures and judge whether a set of sentences were well formed using a five-point Likert scale. Fifty Brazilians from different proficiency levels completed the task and the results suggest that the effects of bilingualism on L1 metalinguistic awareness are not as pervasive as usually reported by language processing studies.

The second article inspects features of the bilingual speech produced by Brazilian Portuguese-English speakers. Engelbert, Kluge and Pescatori examined whether the voice quality of these bilinguals differs when they speak Portuguese, their L1, or English, their L2. The researchers examined a number of acoustic measures of the speech produced by the bilinguals and found important differences for fundamental frequency measures and spectral characteristics 
across languages and according to task type, sex, and age of onset of L2 learning. The results reported by the authors corroborate findings from similar studies that show the effects of different languages on the expression of bilingual speakers' personality traits, as these individuals aim at accommodating to cultural patterns of each language they speak.

Cristófaro Silva and Camargos investigate the emergence of the English rhotic, a retroflex approximant, in the English spoken by Brazilians. They collected data from learners whose L1 (Brazilian Portuguese) contains the retroflex approximant, and from learners who produce the rhotic as a fricative consonant. The study is based on Multirepresentational Models, which advocate that linguistic systems emerge from language use. Their results show that the English rhotic is easily incorporated by Brazilians, even by those whose L2 variety does not contain the retroflex approximant, especially when proficiency is more developed.

Gabriel, Morais and Kolinsky start from an intriguing question: Does learning how to read change information processing and expand the human brain storage capacity? The authors explore this question by reviewing, comparing and contrasting models of memory and executive function. Furthermore, they review relevant studies drawing on behavioral and neuroimaging data and conclude that, due to changes in vision and hearing perceptual systems, learning how to read affects linguistic information processing and storage.

The last article in the cognition section is highly connected with teaching issues as well, given the fact that it examines the relationship between working memory capacity and pre-task planning. More specifically, Guará-Tavares investigates learners' pre-task planning processes, and whether these leaners' working memory capacity influences the type of processes they engage in. The study reports on data from twenty-five Brazilian learners of English who completed a version of the Speaking Span Test (working memory measure) and a picture-cued narrative task (speaking measure). While preparing to perform the narrative task, the learners provided think-aloud protocols prompted by the researcher, and retrospective interviews were conducted immediately after the learners completed the narrative task. Guará-Tavares' findings reveal that learners with higher working memory capacity favor metacognitive strategies while planning the narrative task.

A selection of five articles appears in the teaching and learning section. In the first one, Spinassé and Bolzan report on classroom research conducted to promote peer review in ESL writing. The participants were an eighth-year elementary class attending an English-Portuguese bilingual school in Brazil. The participants were engaged in collaborative writing and the researchers used interviews and questionnaires to elicit the participants' expectations before and after the peer review sections. The findings reveal that the students hold a positive attitude towards peer review.

Schulz and Azevedo investigate how much intermediatelearnersofEnglish fromalanguage program in Brazil understand teachers' speech. Furthermore, the authors elicit these learners' and EFL teachers' beliefs about the ideal features of teacher's speech as a resource to promote the development of learners' listening skill. The researchers recorded one teacher giving a speech to his students and designed a set of comprehension questions to accompany the recording. Two groups of English students were asked to listen to the recorded speech and answer the comprehension questions. Next, the students and a group of teachers were presented with a questionnaire that elicited information about their beliefs regarding the ideal features of teacher's speech. The researchers found high percentages of teacher's speech comprehension for the students, but their results also show that teachers' and students' beliefs about teacher's pedagogical discourse differ in important ways.

The interface between teaching and technology is addressed by two articles in this section. Using an ethnographic approach, Silva investigates the development of technological competence of English teachers in training. The Participants were enrolled in an online course at the university level and used a virtual learning environment to engage in collaborative work and interact. The researcher examined data gathered from the participants' online interactions, personal notes, and a questionnaire. By analyzing these data, Silva concluded that the virtual learning environment 
is a useful means to promote knowledge construction, interaction, collaborative learning, and reflection.

The second article dealing with technology presents a questionnaire that can help to evaluate software programs for pronunciation teaching. Martins, Levis, and Borges designed and tested the reliability and validity of this instrument by inviting EFL/ESL teachers from Brazil and abroad to use the instrument to evaluate a commercial software. The researchers found evidence that their instrument has the potential to help professionals design and evaluate pronunciation teaching software.

The last article in the teaching and learning section explores the connection between critical discourse analysis and language teaching. Zacchi's article discusses how neoliberal values are present in English textbooks adopted by the Brazilian National Textbook Program (PNLD). The author analyzes excerpts and activities present in the Links textbook series, observing that the textbook relies on celebrities to advance neoliberal values, but also promotes social and cultural diversity. The latter feature is one of the requirements of the PNLD, and the author concludes that its presence in the textbook series shows an effort of the commercial editorial market to to meet this important requirement.

Turning to the critical discourse analysis section, Boldyrev and Dubrovskaya discuss sociocultural commitment of Cognitive Linguistics, revealed through context dimensions. The article shows results of a project at Tambov School for Cognitive Linguistics in Russia, which considers the anthropocentric nature of language employing a holistic framework within cognitive linguistics. In the literature review, the article focuses on the relevance of looking at context, and the discussion section presents the static-and-dynamic dimension of context, the collective-and-individual dimension of context, and the metaconceptual dimension of contexts.

Stillin the realm of critical discourse analysis, Gomes is concerned with trans people, sexuality and gender issues. The author investigates Brazilian journalistic media practices regarding the representations of women trans gendered female bodies. The analysis reveals that at least one of the journalistic venues analyzed portrays a positive view of gender as a political act. However, the same view is not found in the discursive constructions of two other journalistic venues.

Figueiredo and Pasquetti draw on the framework of critical discourse analysis to examine a source text and its translation into Brazilian Portuguese, both published online on the Lonely Planet website. The authors scrutinize the texts, their usage of images and web layout and highlight important characteristics of tourism discourse nowadays. With the help of the COPA-TRAD parallel corpus computer tool, the researchers point out important differences between the source text and the target text, such as the use of pronouns and verbal aspect. The analysis shows that the target text is a reduced form of the original one, and that cultural references (e.g., proper names, typical dishes) presented a challenge for the translators.

This issue closes with three articles on translation studies and one article that offers an interface between discourse and cultural studies. Publishing market demands and its effects on literary translation are the foci of Branco and Maia's article. The authors argue that, as the publishing market plays an important role in what should be translated or not, translators need to resort to translation strategies that accommodate these demands and suit the target audience. Branco and Maia conclude that the pressure imposed by the market ends up influencing the formation of cultural identities, as translated work may stop short from exploring its potential to redefine concepts and cultural values.

Klein's article also advances a theoretical discussion about translation. The author discusses three central concepts in the field of translation studies: repetition, originality and translation. Klein focuses most of his discussion on work written by renowned scholars such as Edward Said and Samuel Weber.

Salvadori and Silva examine how the translations of [the] poems of E. E. Cummings into Portuguese contributed to building a canon for the American writer, as well as to establishing important tenants for the Brazilian concrete poetry movement. The article focuses on the translations made by Augusto de 
Campos, who chose to translate Cummings' poems that evidenced the poet's innovative forms.

Marchi and McCarthy's article discusses culture and intercultural understanding. The authors present different views on the issue provided by two cultural anthropologists, Robbins and Geertz; a literary critic, Trilling; and Lewis, a famous writer of both fiction and non-fiction. Throughout the article, the authors propose that language and discourse should be seen as part of culture.

Finally, Gabriel reviews the book Consciousness and the brain: deciphering how the brain codes our thoughts. This book addresses some of the major questions debated by researchers interested in neurolinguistics and language processing.

The variety of topics displayed in this issue of the Ilha do Desterro journal should suit the diverse research interests of our target readers. The Editorial Board thanks all the authors and the reviewer for their valuable contributions.

\section{References}

D’Ely, R. C. S. F. \& Guará-Tavares, M. da G. (2014). Introduction: L2 Learning/teaching and Technology: A 'CALL' for a change? Revista Ilha do Desterro, 66 (1), 9-18.

Heberle, V. \& Veloso, F. O. D. (2013). Introduction: Studies in Multimodality. Revista Ilha do Desterro, 64 (1), 9-13.

Johnson, K. \& Dellagnelo, A. C. K. (2015). L2/FL Teacher Education: Bridging the complexities of teaching and the learning of teaching. Revista Ilha do Desterro, 68 (1), 11-18.

Mota, M. B. (2011). Introduction: Recent Developments in SLA. Revista Ilha do Desterro, 60 (1), 9-14.

Tomitch, L. M. B. (2012). Introduction: The Neuroscience of Reading. Revista Ilha do Desterro, 63 (2), 9-14. 